\title{
Parental knowledge, attitudes and practices regarding antibiotic use for acute upper respiratory tract infections in children: a cross-sectional study in Palestine
}

Sa'ed H. Zyoud ${ }^{1,2,3^{*}}$, Adham Abu Taha ${ }^{4}$, Khulood F. Araj ${ }^{5}$, Islam A. Abahri', Ansam F. Sawalha ${ }^{4}$, Waleed M. Sweileh ${ }^{4}$, Rahmat Awang ${ }^{3}$ and Samah W. Al-Jabi

\begin{abstract}
Background: In primary health care centres, upper respiratory tract infections (URTIs) in children are commonly encountered by physicians. Viruses cause most URTIs, but parents' attitudes often represent an important reason for antibiotic abuse, which leads to the development and spread of antimicrobial resistance. The goal of this study was to examine parents' knowledge, attitudes, and practices (KAP) about antibiotic use for children with URTIs in Palestine.

Methods: A cross-sectional study was performed in primary health care centres in Nablus city from 1 June to 31 October 2012. A questionnaire was developed and administered to determine parents' KAP regarding antibiotic use for their children with URTIs.

Results: Three hundred and eighty-five parents completed the questionnaire. A total of $79.7 \%$ of the parents were attentive to the truth that antibiotic misuse is responsible for bacterial resistance. Only $18.9 \%$ of parents thought that antibiotics did not have any harmful side effects. Fifty nine per cent of parents did not agree that URTIs are mostly viral in origin and are self-limited. Almost $73 \%$ of parents choose antibiotics as a treatment for URTIs, while earache $(68 \%)$ and fever $(64 \%)$ were the most common reasons for which parents expected antibiotics. However, more than $38 \%$ of the parents never asked the paediatrician to prescribe antibiotics, and only $6 \%$ congratulated their paediatricians for not prescribing antibiotics.

Conclusions: Although there is a trusted relationship between parents and paediatricians, Palestinian parents have insufficient knowledge related to antibiotic use for URTIs in children, which results in inappropriate attitudes and practices. Educational interventions for both parents and physicians will reduce unnecessary antibiotic use and resistance.
\end{abstract}

Keywords: Upper respiratory tract infections, Parents, Children, Antibiotic

\footnotetext{
* Correspondence: saedzyoud@yahoo.com

${ }^{1}$ Poison Control and Drug Information Center (PCDIC), College of Medicine and Health Sciences, An-Najah National University, Nablus 44839, Palestine ${ }^{2}$ Department of Clinical and Community Pharmacy, College of Medicine and Health Sciences, An-Najah National University, Nablus 44839, Palestine Full list of author information is available at the end of the article
} 


\section{Background}

In primary health care centres, upper respiratory tract infections (URTIs) in children are commonly encountered by physicians [1-4]. These infections are considered the main cause of absenteeism from schools by children or from work by parents [5]. Furthermore, such infections in children bear a lot of economic burden on parents and healthcare system [5].

The World Health Organization, in its late report released in April 2014, revealed that antibiotic resistance is a serious and growing global problem [6]. Several studies reported the relationship between antibiotic use and the development of resistance [7-9]. Countries consuming the highest amounts of antibiotics have the highest rates of resistance [10]. Despite the fact that the majority of URTIs are viral in origin [11], antibiotic prescribing for URTIs is a common practice in paediatrics [12-14]. It is probable that $20-50 \%$ of all antimicrobial use is medically inappropriate $[15,16]$. Inappropriate prescribing of antibiotics is the most important reason behind the development of antibiotic resistance $[17,18]$.

The main contributors to the development of resistance in children are paediatricians and parents. Parental beliefs and expectations are important factors in determining whether an antibiotic is prescribed. When parents panic about acute illnesses, it leads to more frequent paediatric physician visits for URTIs and, subsequently, unnecessary antibiotic use [19-22]. Therefore, numerous reports have evaluated the factors related to antibiotic overuse. These factors consist of knowledge, attitudes and beliefs regarding antibiotic use [23-25], behaviours $[26,27]$, patient treatment satisfaction, patientdoctor communication, and patient experiences with antibiotics [25-28]. Proper public knowledge and attitude toward antibiotics is an important factor in rational antibiotic use and therefore minimizing development of antibiotic resistance [29]. Unfortunately, the pressure imposed on physicians to meet patients' expectations is a major contributing factor for physicians to prescribe antibiotics for viral URTI [24, 30]. Therefore, parental knowledge, attitude and practice toward antibiotic use in URTI in their children is of great value [24, 31].

Many studies were conducted in Palestine regarding antibiotic misuse and purchasing antibiotics without a prescription [32,33]. These studies evaluated the extent of storage and wastage of antibacterial agents in Palestinian households [34], self-medication with antibiotics [35], and patterns of parenteral antimicrobial prescription among paediatric hospitalised patients [36]. Neither of these studies, nor other studies conducted in Palestine, assessed parents' knowledge, attitudes, and practices (KAP) regarding antibiotic use in URTIs in children. Thus, this study is the first of its kind in Palestine to evaluate parental KAP regarding antibiotic use in paediatrics. This study could provide baseline data for developing strategies for local health authorities' educational purposes.

\section{Methods}

\section{Study area and study design}

A cross-sectional survey was performed in Primary Health Care (PHC) centres in selected areas in Nablus governorate. The study was carried out from June, 1st to the end of October in 2012. The PHC centre's selection was based on geographic clustering sampling to obtain a representative sample of parents. Previously published studies about knowledge and attitudes toward antibiotics have been mostly carried out among physicians in primary healthcare centres $[4,37,38]$. For the purpose of this study, four primary health care centres were chosen. These centres have the followings in common which made them suitable as a study area [39, 40]: (1) they provide a full package of primary health care services; (2) they serve a large number of patients; and (3) they cover the three types of communities within this region (rural, urban, and Palestinian refugee camps). To the best of our knowledge, limited such studies were conducted on consumers such as parents [24, 31].

\section{Study population}

The population of the study was the parents of children attending PHC centres aged between 18 and 50 years.

\section{Sampling procedure and sample size calculation}

Sample size was calculated using a Raosoft sample size calculator. The calculation was based on $50 \%$ response distribution, $5 \%$ margin of error and $95 \%$ confidence interval [41]. The assumption that the response rate is $50 \%$ was based on the idea that both responses and response rates were completely unknown since there are no previously published similar studies from Palestine. The calculated sample size was 377 . To ensure accuracy, the sample size was increased to 400 to account for any missing data or non-response rate. Ultimately, parents were selected using a convenience sampling method because it saves time, cost, and ease of accessibility to the researchers [42].

\section{Questionnaire development}

A self-administered questionnaire was developed in Arabic after reviewing related studies [24, 31, 43]. Most of the developed questions were extracted from previously published validated studies in Greece and were tailored to suit the local situation and assure its applicability [31, 44]. The questionnaire is comprised of four main sections: demographic data related to participants; and knowledge, attitude, and practice concerning the use of antibiotics. Some items were added, and the questionnaire was modified to be used in the Palestinian setting. Content validity 
of the questionnaire was assured by a group of experts in the field of paediatrics, infectious diseases, clinical pharmacy and biostatisticians. A pilot study was conducted among 30 participants in order to check the clarity and readability of the questionnaire. The final version of the questionnaire was refined and corrected based on feedback from the participants.

The final questionnaire consisted of four sections (A, B, C, and D). Section A contained demographic data, including age, gender, education levels, residency, income, number of children, health insurance status and whether the child had a chronic disease such as asthma. Section B was adopted from Panagakou et al., [31] and included items concerning parental knowledge of antibiotics. Parents were requested to mark antibiotic names out of six frequently used medications in the Nablus district and to answer questions related to general antibiotic use, adverse effects and their use in viral infections. Furthermore, Section B explored sources of information regarding the use of antibiotics. Section "C" included items concerning parental attitudes toward antibiotics. Parents were asked for possible treatment options for paediatric URTI management. In addition, parents were asked specifically about the most serious symptoms that would have to be present in order for them to visit the paediatricians' office. Other questions asked if parents thought that antibiotics were useful in relieving a variety of symptoms. Furthermore, parents were asked to indicate their expectations for antibiotic use corresponding to URTI symptoms and to designate the reasons for antibiotic use without medical advice. Finally, Section D illustrated parents' answers to questions linked to the medical practice. Parents were asked to indicate if their paediatrician spends adequate time elucidating the illness and suggesting antibiotic treatment for a child's illness, and if he/she is affected by their demand to prescribe antibiotics for their child. Parents were asked to answer the statements on a 5-point Likert scale ("strongly agree", "agree", "uncertain", "disagree", "strongly disagree" or "never", "sometimes", "often", "most of the time", "always"). A detailed description is provided in Additional file 1 about questions regarding knowledge, attitudes and practices of antibiotic use as an Arabic version.

\section{Ethical approval}

The study was approved by the Palestinian Ministry of Health, and the institutional review board (IRB) of AnNajah National University (approval number 23-Apr 2012 on April 13, 2012) and verbal consent was obtained from survey participants. An written consent was waived according to the regulation of IRB.

\section{Statistical analysis}

Data were entered and assessed with the Statistical Package for the Social Sciences (SPSS), version 16.0 for Windows. The analysis of answers for questions involved descriptive quantitative statistics, e.g., frequency and percentage for categorical variables and means \pm standard deviation (SD) or medians (lowerupper quartiles) for numerical variables. The figures

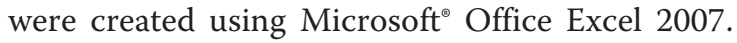

\section{Results}

Three hundred and eighty five questionnaires were collected back out of 400 that were initially distributed, giving a response rate of $96.2 \%$. The majority of respondents $(62.6 \%)$ were mothers with a mean age of 31.6 years $(\mathrm{SD} \pm 7)$, and $74 \%$ of parents considered their income as moderate. Approximately two-thirds of parents lived in the city. Nearly $43 \%$ of participants

Table 1 Socio-demographic characteristics of the population studied $(n=385)$

\begin{tabular}{|c|c|}
\hline Variable & $\begin{array}{l}\text { Frequency (\%), or mean } \pm S D \text {, or } \\
\text { median [interquartile] } N=385\end{array}$ \\
\hline \multicolumn{2}{|l|}{ Gender } \\
\hline Male & $144(37.4)$ \\
\hline Female & $241(62.6)$ \\
\hline Age $\pm S D$ (year) & $31.6 \pm 7$ \\
\hline $\begin{array}{l}\text { Median number of children } \\
\text { aged less than six years }\end{array}$ & $2[1-2]$ \\
\hline $\begin{array}{l}\text { Median number of children } \\
\text { aged more than six years }\end{array}$ & $0[0-2]$ \\
\hline \multicolumn{2}{|l|}{ Health insurance } \\
\hline Governmental insurance & $142(36.9)$ \\
\hline Private insurance & $127(33.0)$ \\
\hline Do not have insurance & $116(30.1)$ \\
\hline \multicolumn{2}{|l|}{ Participant's educational level } \\
\hline Elementary school (primary) & $79(20.5)$ \\
\hline $\begin{array}{l}\text { High school (secondary } \\
\text { school) }\end{array}$ & $149(36.4)$ \\
\hline University & $166(43.1)$ \\
\hline \multicolumn{2}{|c|}{ Income level of the family per month ${ }^{a}$} \\
\hline Low (less than 500 JD) & $67(17.4)$ \\
\hline Average (500-1000 JD) & $285(74)$ \\
\hline High (more than 3000 JD) & $33(8.6)$ \\
\hline \multicolumn{2}{|l|}{ Residency } \\
\hline City & $239(62.1)$ \\
\hline Rural & $101(26.2)$ \\
\hline Palestinian refugee camps & $45(11.7)$ \\
\hline Child with chronic disease & $41(10.6)$ \\
\hline
\end{tabular}

${ }^{\mathrm{a}} 1$ Jordanian Dinar (JD) equals 1.41 US Dollar 
had a university degree. The socio-demographic characteristics of respondents are shown in Table 1.

\section{Knowledge}

Most parents (61.6\%) stated that their physician was the main source of information regarding antibiotics, followed by their pharmacist (34.3\%); other sources, such as television, newspapers, and family members/friends accounted only for $2.8 \%$ of parents' sources of information. However,
$1.3 \%$ of parents stated they never received any information from any of these sources.

When parents were asked to discriminate between antibiotic products and other drugs, including analgesics, cough preparations and expectorants, and antipyretics, most parents $(55.6 \%)$ were able to identify that amoxicillin was an antibiotic, while only 8.1 and $3.1 \%$ were able to identify that amoxicillin-clavulanic acid and cefuroxime, respectively, were antibiotics. Moreover, 24.2, 4.7 and $4.1 \%$ of parents identified ibuprofen,

Table 2 Parental knowledge regarding antibiotic use in children with URTIs $(N=385)$. Questions adopted from Panagakou et al. [31]

\begin{tabular}{|c|c|c|c|}
\hline Variable & Item & Frequency & Percentage \% \\
\hline \multirow[t]{5}{*}{ Antibiotics can be used for any feverish child } & Strongly agree & 76 & 19.7 \\
\hline & Agree & 153 & 39.7 \\
\hline & Disagree & 110 & 28.6 \\
\hline & Strongly disagree & 40 & 10.4 \\
\hline & Uncertain & 6 & 1.6 \\
\hline \multirow{5}{*}{$\begin{array}{l}\text { Children with flu like symptoms get better } \\
\text { faster when antibiotics are used }\end{array}$} & Strongly agree & 69 & 17.9 \\
\hline & Agree & 201 & 52.2 \\
\hline & Disagree & 95 & 24.7 \\
\hline & Strongly disagree & 15 & 3.9 \\
\hline & Uncertain & 5 & 1.3 \\
\hline \multirow{5}{*}{$\begin{array}{l}\text { Most URTIs are viral in origin and are self-limited; } \\
\text { thus, there is no need for antibiotic use }\end{array}$} & Strongly agree & 43 & 11.2 \\
\hline & Agree & 114 & 29.9 \\
\hline & Disagree & 173 & 44.9 \\
\hline & Strongly disagree & 37 & 9.6 \\
\hline & Uncertain & 18 & 4.7 \\
\hline \multirow[t]{5}{*}{ Antibiotics do not have any side effects } & Strongly agree & 19 & 4.9 \\
\hline & Agree & 54 & 14.0 \\
\hline & Disagree & 163 & 42.3 \\
\hline & Strongly disagree & 138 & 35.8 \\
\hline & Uncertain & 11 & 2.9 \\
\hline \multirow{5}{*}{$\begin{array}{l}\text { Inappropriate use of antibiotics reduces their } \\
\text { efficacy and drives bacterial resistance }\end{array}$} & Strongly agree & 126 & 32.7 \\
\hline & Agree & 181 & 47 \\
\hline & Disagree & 53 & 13.8 \\
\hline & Strongly disagree & 15 & 3.9 \\
\hline & Uncertain & 10 & 2.6 \\
\hline \multirow[t]{5}{*}{ Antibiotic use can prevent complications from URTIs } & Strongly agree & 68 & 17.7 \\
\hline & Agree & 223 & 57.9 \\
\hline & Disagree & 63 & 16.4 \\
\hline & Strongly disagree & 12 & 3.1 \\
\hline & Uncertain & 19 & 4.6 \\
\hline \multirow[t]{5}{*}{ Scientists can produce new antibiotics for resistant bacteria } & Strongly agree & 96 & 24.4 \\
\hline & Agree & 180 & 46.8 \\
\hline & Disagree & 27 & 7.0 \\
\hline & Strongly disagree & 18 & 4.7 \\
\hline & Uncertain & 64 & 16.6 \\
\hline
\end{tabular}


paracetamol, and cough preparations, respectively, as antibiotics.

Table 2 demonstrate the responses to questions related to knowledge. A total of $79.7 \%$ of parents were attentive to the truth that antibiotic misuse is responsible for bacterial resistance, but $70.1 \%$ would still give antibiotics to their child because they thought this would lead to a faster recovery. $59 \%$ of parents did not agree that URTIs are mostly viral in origin and are self-limited without the need for antibiotic use. Only $18.9 \%$ of parents thought that antibiotics did not cause any harmful side effects, while $78.1 \%$ were certain that antibiotics might cause many harmful adverse effects (Fig. 1). Moreover, $71.7 \%$ of parents thought that new stronger antibiotics are always emerging.

\section{Attitude and expectation}

When parents were given possible treatment options for the management of paediatric URTIs, more than twothirds $(73.2 \%)$ of participants chose antibiotic therapy, and $66 \%$ of parents choose analgesics and antipyretics as a possible treatment options for URTIs, while only $15.3 \%$ of participants choose inhalers as a possible therapy (Fig. 2). In addition, when parents were asked specifically about the most serious symptoms that would have to be present in order for them to visit the paediatricians office (including fever, runny nose, cough, sore throat, ear pain, and change in behaviour) in the case of URTIs, 78.4 and $44.7 \%$ of symptoms were fever and ear pain, respectively, often accompanied by other symptoms.

Few parents would ask their paediatrician for antibiotics for nasal drainage $(22 \%)$ or dry throat $(11 \%)$, while the majority of parents would want their paediatrician to recommend an antibiotic if their child had an earache (68\%), fever (64\%), cold (52\%), cough (34\%), or was vomiting (30\%). Figure 3 shows parental expectations for antibiotic use corresponding to URTI symptoms. There are many reasons for parents to administer antibiotics to their children without having received previous medical advice. In particular, $24.7 \%$ of parents used antibiotics as selfmedication due to economic hardships or lack of time, while $50.6 \%$ would give antibiotics to their child because they believed that symptoms (e.g., earache, fever, cold, cough) were not dangerous as much as necessary to see the paediatrician.

Figure 4 indicates parental attitudes for antibiotic use in URTIs. The majority of parents $(72.7 \%)$ agreed that antibiotics are extensively used without proper indications and affirmed that they would not change paediatricians if they did not easily prescribe antibiotics (76\%); however, $27 \%$ declared that they would change paediatricians because they easily prescribed antibiotics. About $63.5 \%$ of parents agreed that it was better to keep away from the use of antibiotics to their child for simple or uncomplicated URTIs.

\section{Practice}

Figure 5 illustrates parents' responses to questions related to practice. More than $38 \%$ of parents declared that they never asked their paediatrician to prescribe antibiotics, while only $6 \%$ of parents congratulated paediatricians for not prescribing antibiotics. However, about $41.1 \%$ of parents would ask the paediatrician whether antibiotic administration was necessary. About $28.3 \%$ of parents thought that their paediatrician prescribed antibiotics based on their request, and, more notably, $76.6 \%$ declared they exactly follow paediatricians' directions.

\section{Discussion}

The current study aimed to analyse knowledge and attitudes concerning antibiotic use and practices in the management of childhood URTIs in a large sample of

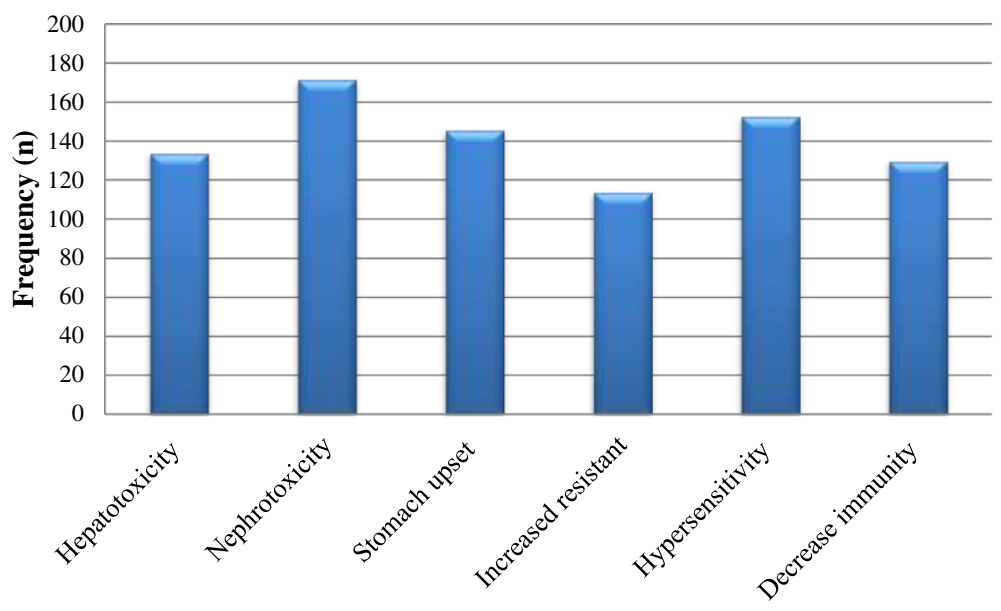

Fig. 1 Parents' knowledge regarding harmful adverse effects of antibiotics 


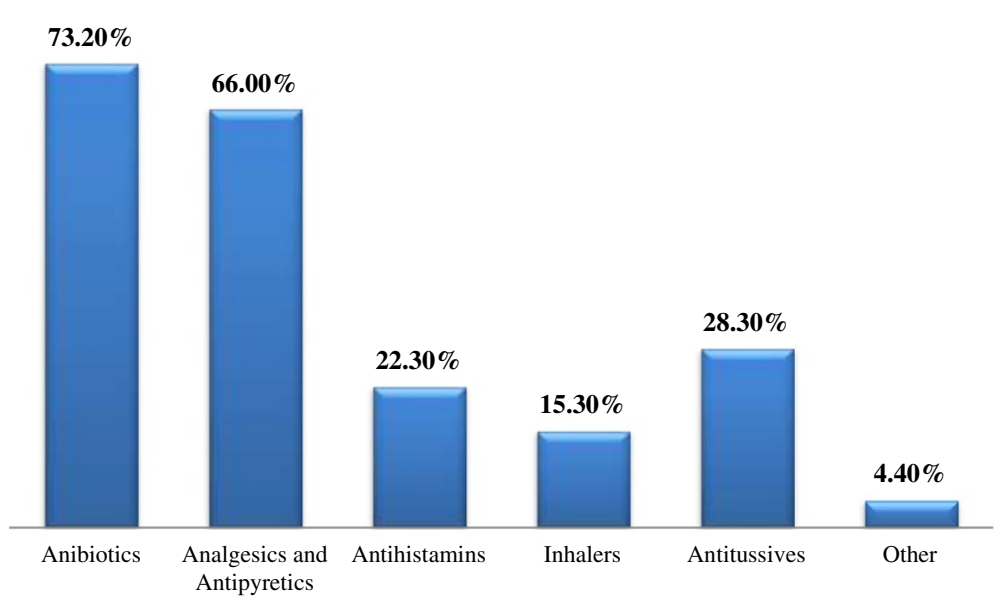

Fig. 2 Parental expected treatment for paediatric URTIs

parents. The issue of the current study is novel in the Palestinian population. It is considered a part of social science that often lags behind.

Our study demonstrated that Palestinian parents and paediatricians have a trusting relationship; the great majority of parents have confidence in the information and prescriptions supplied to them by paediatricians, and only a few parents would change paediatricians if they over- or under-prescribed antibiotics in the case of URTIs in children. Furthermore, $76.6 \%$ stated that they precisely follow paediatricians' recommendations, and almost two-thirds of parents indicated their paediatricians as the main source of information about use or misuse of antibiotics. Xiang et al. [45] identified media (e.g., television) as the main source of such information about use or misuse of antibiotics, despite the fact that similar KAP studies reported paediatricians as the preferred source of information [43].

Most of the Palestinian parents were attentive to the truth that antibiotic misuse is responsible for bacterial resistance, although $59 \%$ of them did not agree that URTIs are mostly viral in origin and are self-limited without the need for antibiotic use, which is in contrast to Greek parents, of which $80 \%$ believed that URTIs are mostly self-limited [31]. It is inaccurate to suppose that $59 \%$ of the parents preferred only antibiotic treatment because most of them also favoured other medications indicated for symptom relief such as analgesics, antipyretic, antihistamines, inhalers, and cough preparations.

Our results demonstrated that fever symptoms accompanied with URTIs were the most common reason for a paediatric visit in which parents would expect to receive

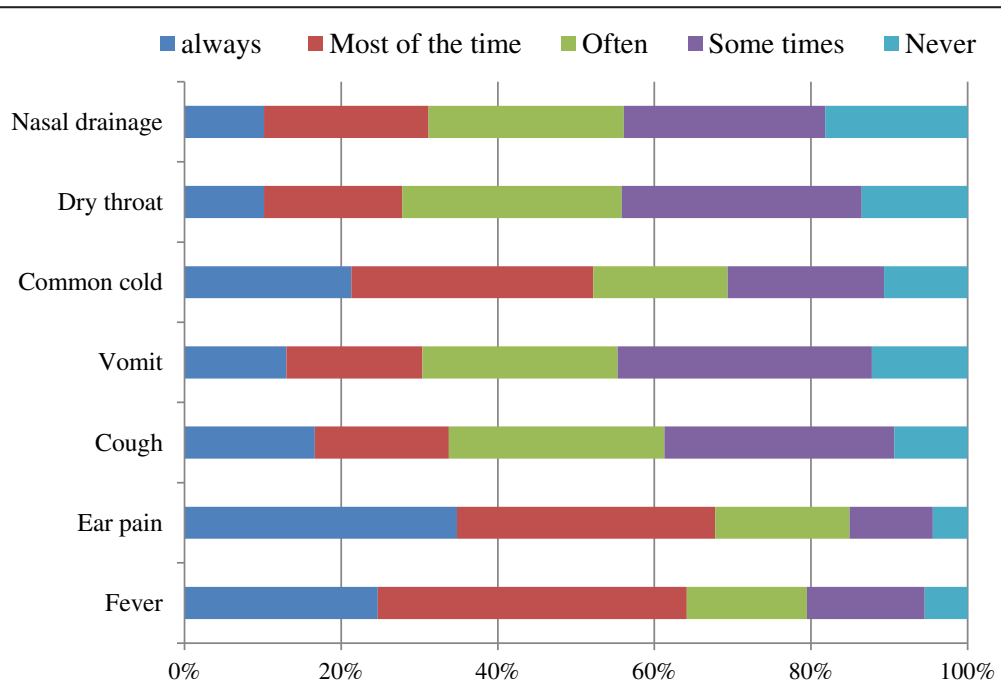

Fig. 3 Parental expectations for antibiotic use corresponding to upper respiratory tract infection symptoms. Questions adopted from Panagakou et al. [31] 


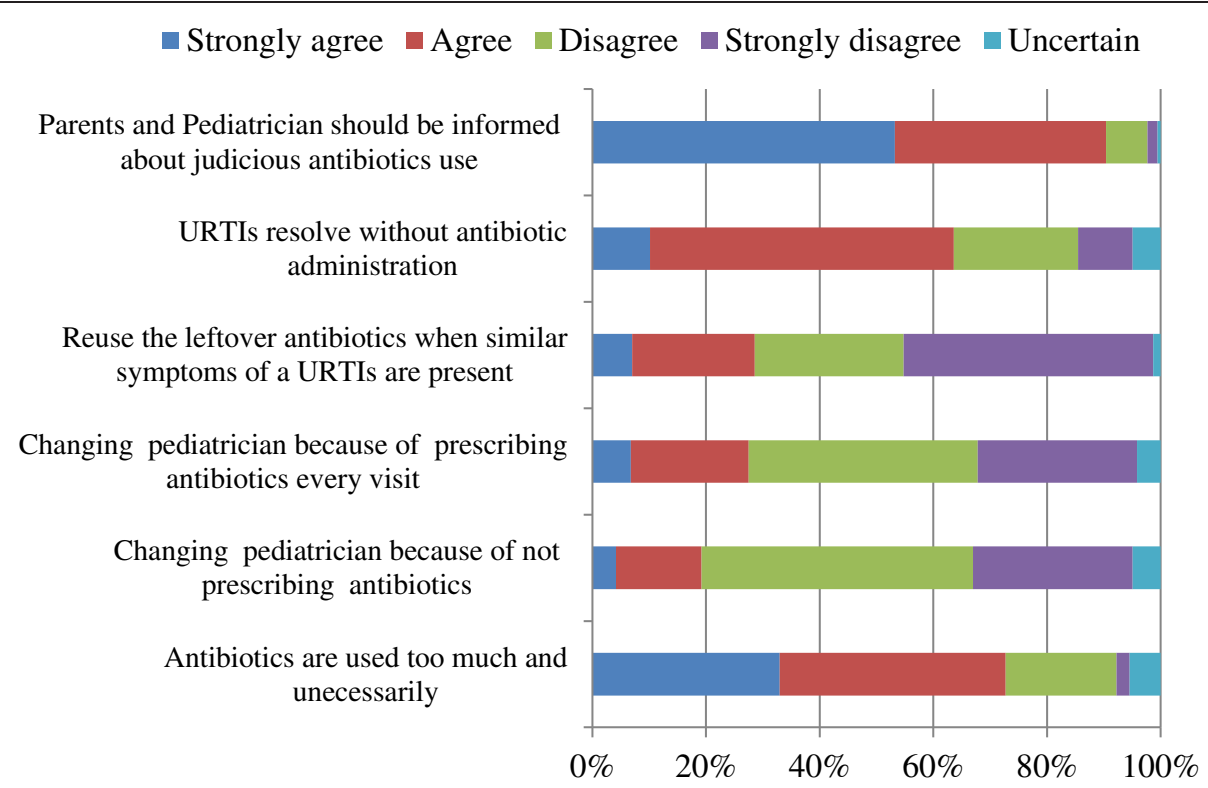

Fig. 4 Percentage of parents' responses to questions related to attitude. Questions adopted from Panagakou et al. [31]

antibiotics. Similarly, a cross-sectional KAP study involving 421 parents in Malaysia showed that $76 \%$ of parents believed that antibiotics were helpful in the treatment of fever [24].

The use of "leftover" and "shared" antibiotics by parents to their child are common situations in the Palestinian and Malaysian communities; $27.6 \%$ of Palestinian parents reused the leftover and shared antibiotics between their children, while $15 \%$ of Malaysian parents reused leftovers and $24 \%$ shared antibiotics. Parents believed that their child complained of the same illnesses because they had similar symptoms, therefore they would give the leftover antibiotics and shared it with others, and only bring their children to paediatrician if there was no improvement [24]. Interestingly, almost $51 \%$ of parents choose antibiotics as the first choice of treatment for URTIs despite $78 \%$ of them understanding that antibiotic use is associated with harmful and adverse effects on body systems, especially nephrotoxicity and hepatotoxicity.

Furthermore, $72.7 \%$ of parents in the current study believed that antibiotics were used too much and unnecessarily. Comparable findings were found in previous similar studies such as Panagakou et al. [31] (78 \%) and Rouusounides et al. [43] (81\%). This could be

\section{$\square$ Always $\square$ Most of the times $\square$ Often $\square$ Some times $\square$ Never}

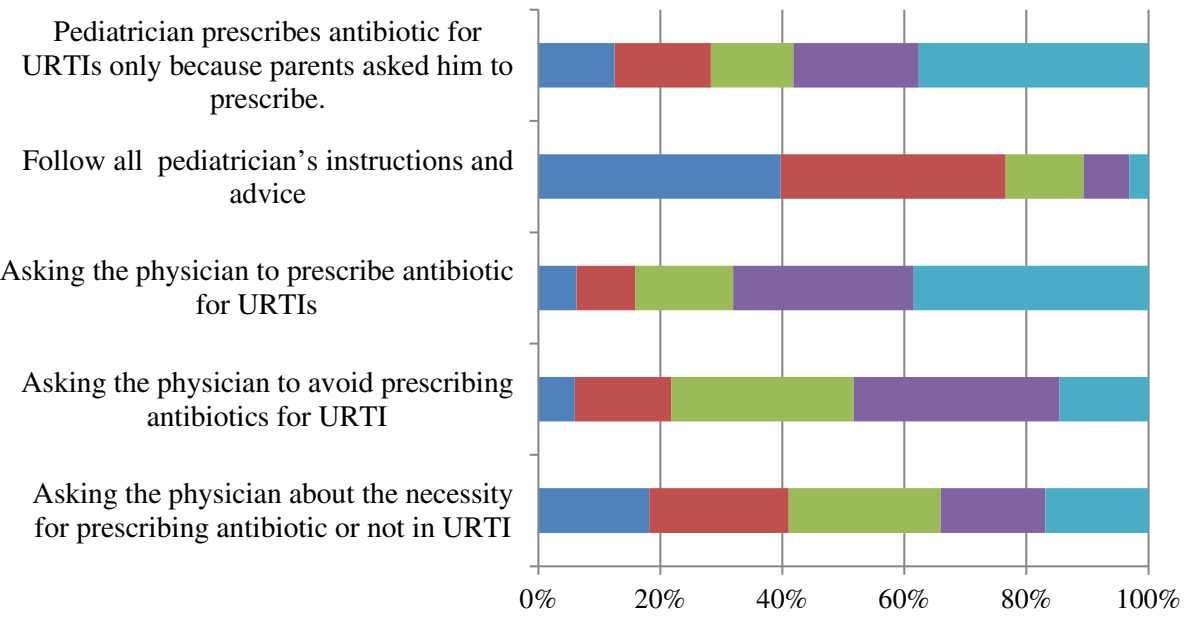

Fig. 5 Percentage of parents' responses to questions related to practice. Questions adopted from Panagakou et al. [31] 
somewhat contributed to by paediatricians' behaviours and their antibiotic prescribing practices in Palestine $[35,36,46,47]$, which is one of the developing countries in the Middle East that has a high antimicrobial resistance rate [32, 48, 49]. There were several factors that may have induced inappropriate antibiotic prescription, including diagnostic uncertainty, sociocultural and economic pressures, lack of knowledge, and fear of litigation [50,51]. A more recent study demonstrated that many general practitioners had a moderate level of knowledge concerning the management of URTIs [4].

\section{Strengths and limitations of the study}

This is the first study that was conducted to assess parental KAP on antibiotic use in URTIs in Palestine. In addition, the study response rate of $96.1 \%$ is considered reasonable for a community survey. Nevertheless, there were some limitations of this study. These limitations were associated with using a convenience sample, which might not be representative of the whole community in Palestine. Furthermore, the data were collected from parents attending PHC centres which limit the generalizability of the results to other types of health care services such as private sectors. While efforts were made to obtain representative samples, the over representation of PHC and higher educational level in the study sample might indicate a possible selection bias. Another limitation is that parents were asked several questions about their experience and antibiotic use in the past, which may lead to recall bias. Lastly, small sample size of the subgroups made comparative analyses to be problematic. For example, comparison between those living in refugee camps and city residents would have been helpful in identifying the most appropriate groups to target with educational programmes.

\section{Conclusions and recommendations}

In conclusion, we found that Palestinian parents' lack of knowledge on antibiotic use for paediatric URTIs resulted in inappropriate attitudes and practices. On the other hand, there is a trusted relationship between parents and paediatricians, and there is confidence in the information and prescriptions provided to them from doctors: only a few parents would change their paediatrician according to antibiotic prescription patterns. However, parents also believed that inappropriate use of antibiotics reduces their efficacy and drives resistance. Unfortunately, a large number of parents did not agree that URTIs are mostly viral of origin; parents' also self-limited antibiotic use, and three-fourths expected antibiotics to be a choice for paediatric URTI treatment. Educational interventions for both parents and physicians will reduce unnecessary antibiotic use and resistance. Strengthening and application of pharmacy regulations related to the over-the-counter sale of antibiotics is needed in community pharmacies.

\section{Additional file}

Additional file 1: Study questionnaires. This is the final version of the Arabic version that was used for assessing parents' knowledge, attitudes, and practices regarding antibiotic use in upper respiratory tract infections in children. (DOCX $36 \mathrm{~kb}$ )

\section{Abbreviations}

URTIs: Upper respiratory tract infections; KAP: Knowledge, attitudes, and practices; PHC: Primary health care; SD: Standard deviation; IRB: Institutional review board.

\section{Competing interests}

The authors declare that they have no competing interests.

\section{Authors' contributions}

SZ led study design, data collection, statistical analysis, interpreted the data, and drafting of manuscript; AA, SA, AS, WS and RA involved in study concept and design, and revised the article for important intellectual content; and KA, and IA carried out the data collection, results tabulation, statistical analysis, and wrote part of the article. All authors read and approved the final manuscript and agreed on its submission.

\section{Acknowledgements}

The research team would like to thank all participants who agreed to complete the survey. Furthermore, the authors would like to express many thanks and gratitude to An-Najah National University and the Palestinian Ministry of Health for their help and ethical approval to conduct this study.

\section{Author details}

${ }^{1}$ Poison Control and Drug Information Center (PCDIC), College of Medicine and Health Sciences, An-Najah National University, Nablus 44839, Palestine. ${ }^{2}$ Department of Clinical and Community Pharmacy, College of Medicine and Health Sciences, An-Najah National University, Nablus 44839, Palestine. ${ }^{3}$ WHO Collaborating Centre for Drug Information, National Poison Centre, Universiti Sains Malaysia (USM), Penang 11800, Malaysia. ${ }^{4}$ Department of Pharmacology and Toxicology, College of Medicine and Health Sciences, An-Najah National University, Nablus 44839, Palestine. ${ }^{5}$ PharmD Program, College of Medicine and Health Sciences, An-Najah National University, Nablus, Palestine.

Received: 18 April 2015 Accepted: 23 October 2015

Published online: 11 November 2015

\section{References}

1. Yang L, Liu C, Wang L, Yin X, Zhang X. Public reporting improves antibiotic prescribing for upper respiratory tract infections in primary care: a matchedpair cluster-randomized trial in China. Health Res Policy Syst. 2014;12:61.

2. Eckel N, Sarganas G, Wolf IK, Knopf H. Pharmacoepidemiology of common colds and upper respiratory tract infections in children and adolescents in Germany. BMC Pharmacol Toxicol. 2014;15:44.

3. Zeng L, Zhang L, Hu Z, Ehle EA, Chen Y, Liu L, et al. Systematic review of evidence-based guidelines on medication therapy for upper respiratory tract infection in children with AGREE instrument. PLoS One. 2014;9(2):e87711

4. Hassali MA, Kamil TK, Md Yusof FA, Alrasheedy AA, Yusoff ZM, Saleem F, et al. General practitioners' knowledge, attitude and prescribing of antibiotics for upper respiratory tract infections in Selangor, Malaysia: findings and implications. Expert Rev Anti Infect Ther. 2015;13(4):511-20.

5. West JV. Acute upper airway infections. Br Med Bull. 2002;61:215-30.

6. WHO. Antimicrobial resistance: global report on surveillance 2014 [http:// apps.who.int/iris/bitstream/10665/112642/1/9789241564748_eng.pdf?ua=1].

7. Turnidge J, Christiansen K. Antibiotic use and resistance-proving the obvious. Lancet. 2005;365(9459):548-9.

8. Levy SB, Marshall B. Antibacterial resistance worldwide: causes, challenges and responses. Nat Med. 2004;10(12 Suppl):S122-9. 
9. Shibl AM, Memish Z, Osoba A. Antibiotic resistance in developing countries. J Chemother. 2001;13 Suppl 1:40-4

10. Ferech M, Coenen S, Malhotra-Kumar S, Dvorakova K, Hendrickx E, Suetens C, et al. European Surveillance of Antimicrobial Consumption (ESAC): outpatient antibiotic use in Europe. J Antimicrob Chemother. 2006;58(2):401-7.

11. Harnden A, Perera R, Brueggemann AB, Mayon-White R, Crook DW, Thomson A, et al. Respiratory infections for which general practitioners consider prescribing an antibiotic: a prospective study. Arch Dis Child. 2007:92(7):594-7.

12. Goossens H, Ferech M, Vander Stichele R, Elseviers M, Group EP. Outpatient antibiotic use in Europe and association with resistance: a cross-national database study. Lancet. 2005;365(9459):579-87.

13. Watson RL, Dowell SF, Jayaraman M, Keyserling H, Kolczak M, Schwartz B. Antimicrobial use for pediatric upper respiratory infections: reported practice, actual practice, and parent beliefs. Pediatrics. 1999;104(6):1251-7.

14. McCaig LF, Besser RE, Hughes JM. Trends in antimicrobial prescribing rates for children and adolescents. JAMA. 2002;287(23):3096-102.

15. Guven GS, Uzun O. Principles of good use of antibiotics in hospitals. J Hosp Infect. 2003;53(2):91-6. quiz 149.

16. Cizman M. The use and resistance to antibiotics in the community. Int J Antimicrob Agents. 2003;21(4):297-307.

17. Nasrin D, Collignon PJ, Roberts L, Wilson EJ, Pilotto LS, Douglas RM. Effect of beta lactam antibiotic use in children on pneumococcal resistance to penicillin: prospective cohort study. BMJ. 2002;324(7328):28-30.

18. Yagupsky P. Selection of antibiotic-resistant pathogens in the community. Pediatr Infect Dis J. 2006:25(10):974-6.

19. Paluck E, Katzenstein D, Frankish CJ, Herbert CP, Milner R, Speert D, et al. Prescribing practices and attitudes toward giving children antibiotics. Can Fam Physician. 2001:47:521-7.

20. Stivers T. Participating in decisions about treatment: overt parent pressure for antibiotic medication in pediatric encounters. Soc Sci Med. 2002;54(7):1111-30.

21. Mangione-Smith R, McGlynn EA, Elliott MN, McDonald L, Franz CE, Kravitz RL. Parent expectations for antibiotics, physician-parent communication, and satisfaction. Arch Pediatr Adolesc Med. 2001;155(7):800-6.

22. Pechere JC. Patients' interviews and misuse of antibiotics. Clin Infect Dis. 2001:33 Suppl 3:S170-3.

23. Awad Al, Eltayeb IB. Self-medication practices with antibiotics and antimalarials among Sudanese undergraduate university students. Ann Pharmacother. 2007:41(7):1249-55.

24. Chan GC, Tang SF. Parental knowledge, attitudes and antibiotic use for acute upper respiratory tract infection in children attending a primary healthcare clinic in Malaysia. Singapore Med J. 2006;47(4):266-70.

25. Mitsi G, Jelastopulu E, Basiaris H, Skoutelis A, Gogos C. Patterns of antibiotic use among adults and parents in the community: a questionnaire-based survey in a Greek urban population. Int J Antimicrob Agents. 2005;25(5):439-43.

26. Al-Azzam SI, Al-Husein BA, Alzoubi F, Masadeh MM, Al-Horani MA. Selfmedication with antibiotics in Jordanian population. Int J Occup Med Environ Health. 2007;20(4):373-80.

27. Sarahroodi S, Arzi A, Sawalha A, Ashtarinezhad A. Antibiotics selfmedication among southern iranian university students. Int J Pharmacol. 2010;6(1):48-52

28. Crossley J, Eiser C, Davies HA. Children and their parents assessing the doctor-patient interaction: a rating system for doctors' communication skills. Med Educ. 2005:39(8):820-8.

29. Awad Al, Aboud EA. Knowledge, attitude and practice towards antibiotic use among the public in Kuwait. PLoS One. 2015;10(2):e0117910.

30. Belongia EA, Naimi TS, Gale CM, Besser RE. Antibiotic use and upper respiratory infections: a survey of knowledge, attitudes, and experience in Wisconsin and Minnesota. Prev Med. 2002;34(3):346-52

31. Panagakou SG, Spyridis N, Papaevangelou V, Theodoridou KM, Goutziana GP, Theodoridou MN, et al. Antibiotic use for upper respiratory tract infections in children: a cross-sectional survey of knowledge, attitudes, and practices (KAP) of parents in Greece. BMC Pediatr. 2011;11:60.

32. Hajjaj MZA-A. Utilization of antibiotics in Nablus City-Palestine pharmacoepidemiological study. Nablus: National University; 2005.

33. Sawalha AF, Sweileh WM, Zyoud SH, Al-Jabi SW, Shamseh FFB, Odah AA. Analysis of prescriptions dispensed at community pharmacies in Nablus, Palestine. East Mediterr Health J. 2010;16(7):788-92
34. Sawalha A. Extent of storage and wastage of antibacterial agents in Palestinian households. Pharm World Sci. 2010;32(4):530-5.

35. Sawalha AF. Self-medication with antibiotics: A study in Palestine. Int J Risk Saf Med. 2008;20(4):213-22.

36. Sawalha A, Al-Bishtawi G, Al-Khayyat L, Sweileh W, Al-Ramahi R, Jaradat N. Pattern of parenteral antimicrobial prescription among pediatric patients in Al-watani governmental hospital in Palestine. An-Najah Univ J Res. 2006;20:191-206.

37. Sahin H, Arsu G, Koseli D, Buke C. Evaluation of primary health care physicians' knowledge on rational antibiotic use. Mikrobiyol Bul. 2008:42(2):343-8.

38. Md Rezal RS, Hassali MA, Alrasheedy AA, Saleem F, Md Yusof FA, Godman B. Physicians' knowledge, perceptions and behaviour towards antibiotic prescribing: a systematic review of the literature. Expert Rev Anti Infect Ther. 2015;13(5):665-80.

39. Zyoud SH, Al-Jabi SW, Nabulsi MM, Tubaila MF, Sweileh WM, Awang R, et al. The validity and reliability of the parent fever management scale: A study from Palestine. Matern Child Health J. 2015;19(8):1890-7.

40. Zyoud SH, Al-Jabi SW, Sweileh WM, Nabulsi MM, Tubaila MF, Awang R, et al. Beliefs and practices regarding childhood fever among parents: A crosssectional study from Palestine. BMC Pediatr. 2013:13:66.

41. Raosoft Inc. Sample size calculator [http://www.raosoft.com/ samplesize.html].

42. van der Deijl M, Etman A, Kamphuis CB, van Lenthe FJ. Participation levels of physical activity programs for community-dwelling older adults: a systematic review. BMC Public Health. 2014;14:1301.

43. Rousounidis A, Papaevangelou V, Hadjipanayis A, Panagakou S, Theodoridou M, Syrogiannopoulos G, et al. Descriptive study on parents' knowledge, attitudes and practices on antibiotic use and misuse in children with upper respiratory tract infections in Cyprus. Int J Environ Res Public Health. 2011;8(8):3246-62.

44. Panagakou SG, Theodoridou MN, Papaevangelou V, Papastergiou P, Syrogiannopoulos GA, Goutziana GP, et al. Development and assessment of a questionnaire for a descriptive cross-sectional study concerning parents' knowledge, attitudes and practises in antibiotic use in Greece. BMC Infect Dis. 2009;9:52.

45. Xiang $N$, Shi $Y$, Wu J, Zhang S, Ye M, Peng Z, et al. Knowledge, attitudes and practices (KAP) relating to avian influenza in urban and rural areas of China. BMC Infect Dis. 2010;10:34

46. Abu-Taha AS, Sweileh WM. Antibiotic resistance of bacterial strains isolated from patients with community-acquired urinary tract infections: An exploratory study in Palestine. Curr Clin Pharmacol. 2011;6(4):304-7.

47. Al-Dawodi R, Farraj MA, Essawi T. Antimicrobial resistance in non-typhi Salmonella enterica isolated from humans and poultry in Palestine. J Infect Dev Ctries. 2012;6(2):132-6.

48. Shibl A, Daniels J, Sievers J, the SOAR in AME Study Group. Antimicrobial resistance among Streptococcus pneumoniae and Haemophilus influenzae from Africa and the Middle East: 2002- 2003 winter season, Clin Microbiol Infect. 2004;10(Suppl 3):111.

49. de Andrade SS, Gales AC, Sader HS. Antimicrobial resistance in Gramnegative bacteria from developing countries. In: DeJSosa A, Byarugaba DK, Amábile-Cuevas CF, Hsueh PR, Kariuki S, Okeke IN, editors. Antimicrobial resistance in developing countries. New York, Dordrecht, Heidelberg London: Springer; 2010. p. 249-66.

50. Moro ML, Marchi M, Gagliotti C, Di Mario S, Resi D. Why do paediatricians prescribe antibiotics? Results of an Italian regional project. BMC Pediatr. 2009:9:69.

51. Pichichero ME. Understanding antibiotic overuse for respiratory tract infections in children. Pediatrics. 1999;104(6):1384-8. 